\title{
Current Progress and Challenges to Tobacco Control in China
}

\author{
Dong Sun ${ }^{1} ;$ Yuanjie Pang ${ }^{1} ;$ Jun Lyu ${ }^{1,2, *} ;$ Liming $\mathrm{Li}^{1,2, *}$
}

In May 2003, the World Health Organization (WHO) Framework Convention on Tobacco Control (FCTC) was released (1), which is an event of great significance in the history of tobacco control. The FCTC was signed by China in November 2003 and entered into force in January 2006. Although some achievements in tobacco control have been made over the past 15 years, much more progress is needed. In July 2021, the WHO Report on the Global Tobacco Epidemic (Report) was released. The Report evaluates and grades implementation of the 6 most effective strategies of the Monitor, Protect, Offer, Warn, Enforce and Raise (MPOWER) tobacco control package in 61 high-income countries, 105 middleincome countries, and 29 low-income countries (2) (Table 1). This article summarizes current progress and challenges to tobacco control in China with reference to the Report.

\section{PROGRESS AND PROBLEMS OF FCTC IMPLEMENTATION}

\section{Monitor Tobacco Use and Prevention Policies (Grade I for China)}

China's monitoring of tobacco use and prevention policies were highly acclaimed and recommended in the Report (2). Since 1984, 9 nationally representative tobacco use surveys have been conducted in China - 6 among adults (in 1984, 1996, 2002, 2010, 2015, and 2018) and 3 among adolescents (1999, 2004, and 2013) (3). These surveys played critically important roles by providing data to inform policymaking.

\section{Protect People from Tobacco Smoke (Grade IV for China)}

According to the FCTC, by 2011, China should have achieved completely smoke-free public transport, indoor workplaces, indoor public places, and other public places (1). However, as of publication of this article, the only complete smoking ban has been on public transport (2). Although more than 20 provincial-level administrative divisions (PLADs) or cities, including Beijing, Shanghai, Henan, Shenzhen, and Xi'an, have implemented comprehensive smokefree legislation (4), it is apparent that reliance on sporadic, local legislation is insufficient to protect the vast majority of the Chinese population.

The prevalence of second-hand smoke exposure among Chinese aged 15 years and above was $72.4 \%$ in 2010 , decreasing slightly to $68.1 \%$ by 2018 (5). As of December 2021 , only $14 \%$ of the total population (approximately 198 million people) was protected by smoke-free laws (4). The Healthy China Initiative (2019-2030) set a target to have $30 \%$ of the population protected by comprehensive smoke-free laws by 2022 and over $80 \%$ by 2030 , leaving a large gap between the current status and the targets (G).

\section{Offer Help to Quit Tobacco Use (Grade II for China)}

Since 2015, China has actively promoted tobacco cessation services. Efforts include providing access to training for health professionals on how to help patients quit smoking, promoting brief cessation services, standardizing tobacco cessation clinics, and supporting establishment of a "12320" national quit smoking hotline (quit-line) in all PLADs.

However, the national tobacco use survey in 2018 showed that use of the cessation services was extremely low. Of those who attempted to quit smoking, only $3.2 \%$ have called quit-lines and only $4.6 \%$ used cessation drugs or visited cessation clinics (5). Cessation drugs have yet to be covered by basic health insurance schemes, decreasing utilization of and allocation in the cessation clinics ( 7$)$.

\section{Warn About the Dangers of Tobacco (Grade I and III for China)}

This strategy includes two parts. The first part is anti-tobacco mass media campaigns, and for this part, China was graded I (2). Nonetheless, the messaging of smoking being harmful to health is usually nonspecific and often presented in unattractive forms. Antitobacco mass media campaigns in China have largely 


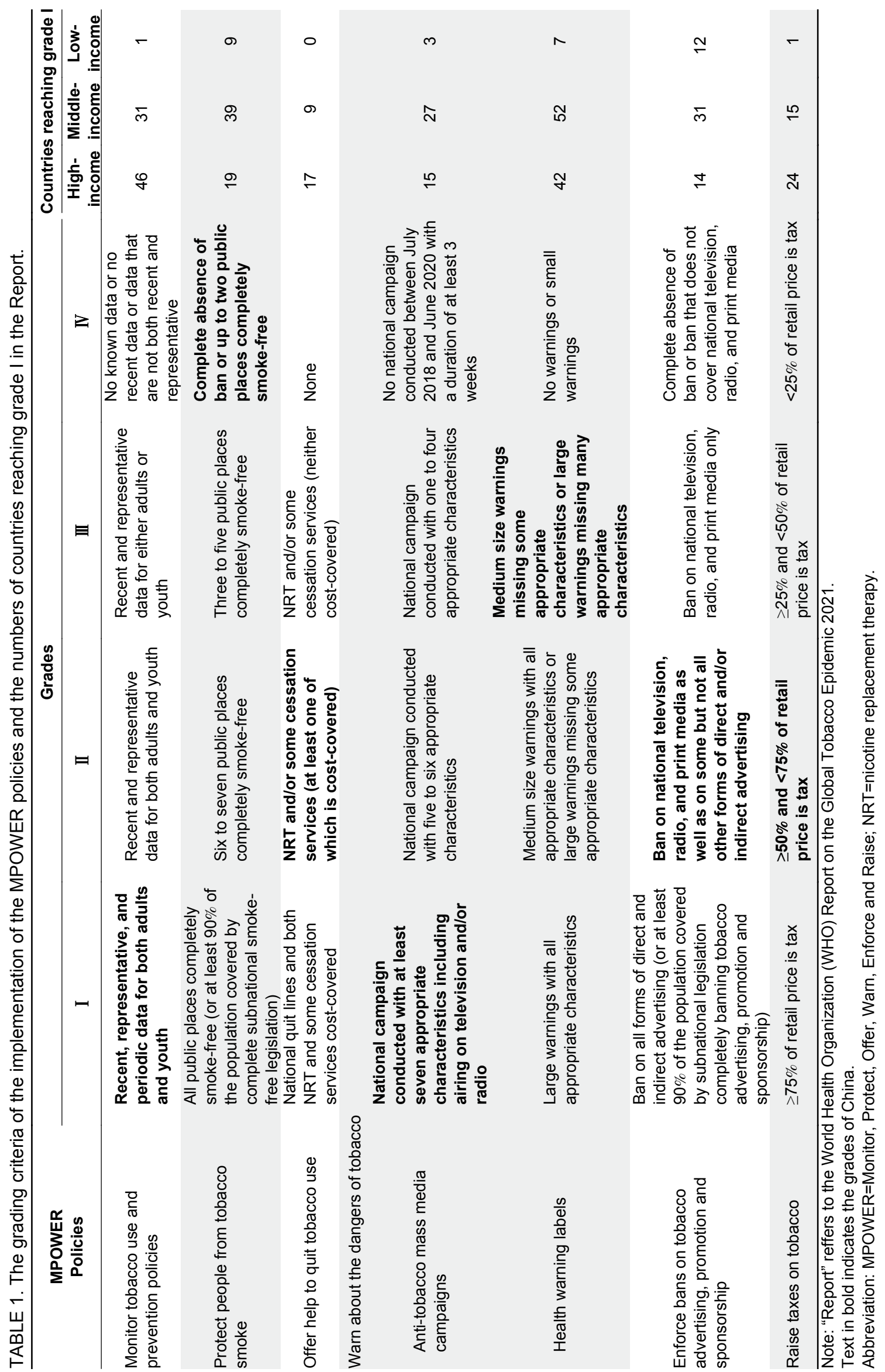


not achieved the expected results. In 2018, only $36.4 \%$ of the public knew that smoking increases risk of stroke, heart disease, and lung cancer (5). Awareness of the health risks of smoking was particularly weak in rural areas.

The second part of the strategy is the use of health warning labels on packages of tobacco products, and for this part, China was graded III (2). China should have implemented effective packaging and labeling measures by 2009 (1). However, until 2017, the Rules on Cigarette Package Labeling in the Territories of the People's Republic of China (Rules) released by the State Tobacco Monopoly Administration (STMA) and the General Administration of Quality Supervision, Inspection, and Quarantine, were not fully in compliance with FCTC requirements and guidelines, which include, for example, the size, location, and wording of health warning labels $(1,8-9)$. Chinese cigarette packages seem insistent on being "beautiful and fascinating," without using full-color pictorial warning and without describing the specific adverse health effects of tobacco. The Canadian Cancer Society released an international report in 2021 that ranked 206 countries or jurisdictions on the effectiveness of their health warnings on cigarette packages (10). According to the report, 134 countries or jurisdictions, covering $70 \%$ of the world's population, fulfilled requirements for pictorial warnings; China, however, ranked $136(10)$.

\section{Enforce Bans on Tobacco Advertising, Promotion, and Sponsorship (Grade II for China)}

The Advertising Law of the People's Republic of China (Advertising Law) revised in 2015 bans tobacco advertisements on mass media, in public places, on public transports, and outdoors (11). Publication of indirect tobacco advertisements through advertisements on any other goods or public service advertisements is also prohibited by the Advertising Law. However, since there is no clear definition of public places in the Advertising Law, tobacco companies can take advantage of this legal advertising loophole. The Charity Law of the People's Republic of China and Interim Measures for the Administration of Internet Advertising, released in 2016, prohibited promotion of tobacco products through charitable donations or the Internet (12-13). However, this law does not clearly regulate other forms of sponsorship, such as student grants and donations from other fundraising activities. Partial bans on tobacco advertising and promotion have little effect because tobacco companies can easily shift resources to forms that are not banned (2).

At present, there are still tobacco advertisements and promotions at sales points and Internet-based media. The national tobacco use survey in 2018 showed that the proportions of the population seeing tobacco advertisements on traditional media such as TV, billboards, posters, newspapers, and magazines decreased compared with 2010 (5). In contrast, the proportion seeing tobacco advertisement at sales points and on the Internet increased. About two thirds of the public has seen smoking scenes in movies or TV series, and in 2018, there were 133 WeChat official accounts for tobacco advertising detected (14).

\section{Raise Taxes on Tobacco (Grade II for China)}

Raising tobacco excise taxes and prices is the single most effective strategy for reducing tobacco use, especially among adolescents and people with lowincomes. According to the guidelines for implementation Article 6 of the FCTC (15), a specific tax is more effective than an ad valorem tax if the specific tax is adjusted with consumer price index. Since the FCTC came into force in 2006, tobacco taxes have been raised twice in China. Tobacco tax reform in 2009 increased ad valorem tax rates at the producer price level and imposed an additional ad valorem tax at the wholesale price level. Although this adjustment increased government revenue, the higher tax amount was not passed on to consumers because STMA reduced profits at the wholesale level. As a result, cigarette sales did not decline. The 2015 tobacco tax reform raised ad valorem tax rates and levied specific taxes at wholesale prices. This adjustment resulted in a slight increase in the retail price of cigarettes on average by $11 \%$ and a $7.8 \%$ decrease in annual cigarette sales (16). However, cigarette sales began rising again in 2017 (3).

FCTC recommends that share of total taxes in retail price of the most widely sold cigarette brand should be $\geq 75 \%$; in China that percentage is only $54.5 \%$ (2). In addition, according to the Report, cigarettes in China have become more affordable since 2010. In other words, increases in tobacco taxes did not offset inflation and income growth, leading to overall less expensive cigarettes in China. The national tobacco survey in 2018 showed that the median price paid for a 
pack of 20 cigarettes was 9.9 CNY, with no change compared with that in 2015 (5).

\section{CHALLENGES AND RECOMMENDATIONS}

During the 15 years since the FCTC came into force in China, some progress has been made towards fulfilling the obligations. However, there are still big gaps in FCTC implementation. The root causes of these gaps are obstacles from the tobacco industry and the government's ambiguous attitudes toward the tobacco economy (3). The tobacco industry of China is state-owned and adopts a system of unified leadership and monopolized operation, with the STMA and the China National Tobacco Corporation (CNTC) being jointly responsible for centralized management. Until now, STMA remains a member of the Leading Group for Inter-Ministerial Coordination for the Implementation of the WHO FCTC (Leading Group). Such a situation provides an opportunity for the tobacco industry to interfere with formulation and implementation of effective tobacco control policies. For example, little progress has been made on the health warning labels which are the responsibility of CNTC/STMA. CNTC/STMA uses its influence to weaken tax policies on tobacco sales and hinder enactment of national smoking-free laws. In the context of the steady growth of China's economy, local governments are even less determined to implement tobacco control policies due to the large proportion of tobacco industry in the governments' tax revenue.

The prevalence of smoking among people 15 years and older in China was $26.6 \%$ in 2018 - almost unchanged from 2010 (5). Healthy China 2030 set a smoking prevalence target of $20 \%$ by 2030 (17). However, the target will be challenging to achieve without removing obstacles from the tobacco industry. An enormous structural change should start by removing CNTC/STMA from the Leading Group. After that, several recommendations for better implementation of the FCTC can be considered, including the following: 1) enacting a national smokefree law, without any exceptions or legal loopholes; 2) having smoking cessation services covered by basic health insurance schemes; 3) putting large pictorial health warnings on all tobacco packages; 4) strengthening regulation of tobacco advertising and promotions on the Internet and sales points and strengthening regulation of smoking scenes in movies and TV series; and 5) adopting stronger and more effective tax and price measures by relying more on a uniform specific taxes that is regularly increased in line with inflation.

In conclusion, changes must be made top-down to remove all the obstacles described above. The Healthy China 2030 blueprint puts health at the center of the country's entire policymaking machinery and requires implementing health in all policies (17). Fulfillment of FCTC obligations is the best way to put into practice the core principles of Healthy China 2030.

Conflicts of interest: No conflicts of interest.

Funding: Reforming the Public Health Preparedness and Response of China: from Evidence to Policy Recommendations. China Medical Board (20-366).

doi: $10.46234 / \mathrm{ccdcw} 2022.020$

\# Corresponding authors: Jun Lyu, lvjun@bjmu.edu.cn; Liming Li, lmlee@bjmu.edu.cn.

${ }^{1}$ Department of Epidemiology \& Biostatistics, School of Public Health, Peking University, Beijing, China; ${ }^{2}$ Peking University Center for Public Health and Epidemic Preparedness \& Response, Beijing, China.

Submitted: January 06, 2022; Accepted: February 08, 2022

\section{REFERENCES}

1. World Health Assembly. WHO framework convention on tobacco control. World Health Organization. 2003. https://apps.who.int/iris/ handle/10665/78302. [2021-12-15].

2. World Health Organization. WHO report on the global tobacco epidemic 2021: addressing new and emerging products. 2021. https:// www.who.int/publications/i/item/9789240032095. [2021-12-15].

3. Yang GH. Tobacco control in China. Beijing: China Union Medical College Press. 2018. http://product.dangdang.com/1856778798.html. (In Chinese).

4. CaiXin. Progress of smoke-free legislation in healthy China. https:// datanews.caixin.com/interactive/2020/smokefree-digital-map. [202112-15]. (In Chinese).

5. Li XH. China adult tobacco survey report 2018. Beijing: People's Medical Publishing House. 2020. (In Chinese).

6. National Health Commission. Healthy China initiative (2019-2030). 2019. http://www.gov.cn/xinwen/2019-07/15/content_5409694.htm. [2021-12-15]. (In Chinese).

7. Xie L, Tan DX, Yang Y, Xiao L. Current situation of smoking cessation clinics in essential public health projects from 2019 to 2020. Chin J Health Educ 2021;37(3):195 - 8. http://dx.doi.org/10.16168/j.cnki. issn.1002-9982.2021.03.001. (In Chinese).

8. State Tobacco Monopoly Administration, General Administration of Quality Supervision, Inspection, and Quarantine. Rules on cigarette package labeling in the territories of the People's Republic of China. 2017. http://www.tobacco.gov.cn/gjyc/tzgg/202101/b9c9c6a9f4a44949 b05cb3ee10045a8a.shtml. [2021-12-15]. (In Chinese).

9. World Health Organization. Guidelines for implementation of Article 11 of the WHO framework convention on tobacco control. 2008. https://www.who.int/fctc/treaty_instruments/adopted/article_11/en/. [2021-12-15].

10. Canadian Cancer Society. International report on cigarette package health warnings. 2021. https://cancer.ca/en/about-us/media-releases/ 2021/international-warnings-report-2021. [2021-12-15]. 
11. Standing Committee of the National People's Congress. Advertising law of the People's Republic of China. 2015. https://www.chinacourt.org/ law/detail/2015/04/id/148192.shtml. [2021-12-15]. (In Chinese).

12. Standing Committee of the National People's Congress. Charity law of the People's Republic of China. 2016. https://www.chinacourtCan.org/ law/detail/2016/03/id/148647.shtml. [2021-12-15]. (In Chinese).

13. State Administration for Industry and Commerce of the People's Republic of China. Interim measures for the administration of internet advertising. 2016. http://www.gov.cn/xinwen/2016-07/09/content_508 9902.htm. [2021-12-15]. (In Chinese).

14. ThinkTank Research Center for Health Development. Tobacco control in China: a civil society perspective 2018. 2019. http://guoqing.china. com.cn/2019-09/04/content_75151270.html. [2021-12-15]. (In Chinese).

15. World Health Organization. Guidelines for implementation of Article 6: price and tax measures to reduce the demand for tobacco. 2013. https://fctc.who.int/publications/m/item/price-and-tax-measures-toreduce-the-demand-for-tobacco. [2021-12-15].

16. Goodchild M, Zheng R. Early assessment of China's 2015 tobacco tax increase. Bull World Health Organ 2018;96(7):506 - 12. http://dx.doi. org/10.2471/BLT.17.205989.

17. The Communist Party of China Central Committee, the State Council. Healthy China 2030 blueprint. 2016. http://www.gov.cn/xinwen/201610/25/content_5124174.htm. [2021-12-15]. (In Chinese). 